\title{
Engaging colleagues in active learning pedagogies through mentoring and co-design
}

Rhys Adams, Kevin Lenton

Rhys Adams, Kevin Lenton, "Engaging colleagues in active learning pedagogies through mentoring and co-design," Proc. SPIE 10452, 14th Conference on Education and Training in Optics and Photonics: ETOP 2017, 104522D (16 August 2017); doi: 10.1117/12.2266663

SPIE Event: 14th Conference on Education and Training in Optics and Photonics, ETOP 2017, 2017, Hangzhou, China 


\title{
Engaging colleagues in active learning pedagogies through mentoring and co-design
}

\author{
Rhys Adams and Kevin Lenton \\ Department of Physics, CEGEP Vanier College \\ 821 Sainte-Croix, Montreal, Canada, H4L 3X9 \\ E-mail: adamsr@vanier.college, lentonk@vanier.college
}

\begin{abstract}
When implemented correctly, active learning pedagogies increase student engagement with discipline content. In addition, there is accumulating evidence that they also positively impact the learning of this content. This is particularly relevant for teaching science disciplines because many students perceive science as being difficult to fully understand. However, an ongoing problem is that instructors have difficulty implementing active learning pedagogies effectively and therefore see no benefit to it. Without persistence or guidance, instructors can become discouraged and return to a more traditional style of teaching. We report on how the Faculty of Science at Vanier College is getting more instructors to engage in active learning pedagogies through mentoring and activity co-design.
\end{abstract}

Keywords: active learning, pedagogical research, STEM education

\section{INTRODUCTION}

Active learning is a pedagogical approach where students are engaged in classroom activities, as opposed to passively listening to lectures. In a more traditional style of teaching, the instructor does most of the talking, restricting opportunities for dialogue between instructors and students. In an active learning setting, the students are at the center of the activity. The instructor leads and scaffolds meaningful activities that facilitate student engagement between the students themselves and with the subject matter. There is accumulating evidence that active learning techniques, when implemented correctly, positively impact the learning of subject matter (including student success as well as understanding fundamental concepts), motivation towards the subject matter, and retention in STEM (science, technology, engineering and math)-based programs [1-7]. However, instructors do not embrace active learning [8-9]. In addition to having misconceptions towards active learning, a big problem is that instructors have difficulty implementing active learning pedagogies and therefore see no benefit to it. Without persistence or guidance, instructors get discouraged and return to a more traditional style of teaching. We report on how the Faculty of Science at Vanier College is encouraging more instructors to engage in active learning pedagogies through activity co-design and mentoring.

Activity co-design refers to when pedagogy researchers and instructors collaborate on the design of new active learning pedagogies. For example, multi-stage (pre-, in- and post-class) activities for college physics have been developed. They use web-based educational platforms, and employ peer instruction and flipped classroom approaches. Students engage with Newton's laws, conservation laws, wave theory, etc. via group analysis of photos of everyday events (sports, transportation, information technology, music, etc.) taken by students. As part of the research, we examine the different orchestration styles that instructors use when implementing these new activities, the evolution of student artifacts (including their quality and correctness), and the rationales students provide when answering test/exam questions.

Mentoring occurs when instructors, who are more skilled at implementing active learning pedagogies successfully (mentors), work closely with other instructors (mentees) to support them, as they implement active learning pedagogies in the classroom. By supporting colleagues into their first active learning implementations, we provide these instructors with a positive experience such that they wish to continue using these pedagogies in the future.

14th Conference on Education and Training in Optics and Photonics: ETOP 2017, edited by Xu Liu,

Xi-Cheng Zhang, Proc. of SPIE Vol. 10452, 104522D · C 2017 ICO, IEEE, OSA, SPIE

CCC code: $0277-786 \mathrm{X} / 17 / \$ 18 \cdot$ doi: $10.1117 / 12.2266663$

Proc. of SPIE Vol. 10452 104522D-1 
These initiatives have also helped foster a community of practice at the college. We hold regular informal meetings where instructors and pedagogical advisors from all disciplines are welcome to discuss active learning, and exchange ideas and expertise. New multidisciplinary collaborations have started between the science disciplines (physics, chemistry, biology and mathematics) and joint-activities developed which highlight, to students and instructors alike, how all their science courses taken in college are interconnected.

\section{THE QUEBEC COLLEGE SYSTEM AND ITS PHYSICS CLASSROOM}

The Quebec (provincial) education system is unique compared with elsewhere in Canada and North America. Students complete their formal high school training after grade 11. Those wishing to pursue careers requiring university training in STEM-related fields must first complete a two year (4 semesters; each 15 weeks long) pre-university Natural Science program at a college (referred to as CEGEP). These two years are designed to replace grade 12 and the freshman year in university, which are the norm throughout other North American education systems. The goals of the Cegep system include preparing students for their future studies, and allowing students more flexibility in exploring which field of study they wish to pursue at university. Quebec students then complete their university undergraduate degrees, typically in 3 years for science and 3.5-4 years for professional programs.

While at college, natural science students take 12 courses related to mathematics, physics, chemistry, and biology (in addition to general studies and complementary courses). At Vanier College, the order of the three physics core courses is: Classical Mechanics, Waves and Modern Physics, followed by Electricity and Magnetism. A typical class size is about 35 students (split into 2 groups for laboratory sessions), with 5-6 hours of class time per week for class lectures, activities and laboratory experiments.

As is the case for university instructors, college instructors in Quebec are required to have the necessary background and training in their discipline (i.e. physics instructors are required to have a degree in physics) but are not required to have been trained in pedagogy. As a result, there are opportunities for professional development and support for instructors wishing to explore and experiment with different teaching styles. For example, SALTISE (Supporting Active Learning \& Technological Innovation in Studies of Education, www.saltise.ca) is a community of practice that brings together instructors, researchers and professionals from colleges and universities in the Montreal area; one of their key objectives is promoting and supporting active learning pedagogies. Both authors are part of SALTISE, one (KL) is a founding member and the other (RA) is regularly involved in testing new activities and digital platforms. Via our involvement with the SALTISE community of practice, we have gained experience and have become more skilled at implementing active learning pedagogies successfully. Some pedagogies that we use, either in a regular or flipped classroom setting, include group work, peer instruction [5-7] (including using personal response systems or clickers [6]), problem/project based learning (PBL, for example see [10]), reflective writing exercises [11], computer/ICT based activities [12-16], incorporating creativity [17-18] and learning outside of the classroom (i.e. class outings) [19].

\section{CO-DESIGNING ACTIVE LEARNING PEDAGOGIES}

Active learning pedagogies are meant to be engaging for the students, but ultimately, instructors must assure that learning is achieved. For example, in physics, students often come to class with misconceptions; and having the students learn physics correctly, is our challenge. Once a desired learning outcome is identified, pedagogy researchers and instructors collaborate on the design of a new active learning pedagogy. It is an iterative process that involves feedback, not only between the pedagogy researchers and instructors, but also with students via its implementation.

In the co-design process, the following three aspects need to be considered:

1. Discipline content: For example, designing an activity that will help students understand Newton's third law force pairs.

2. Resources available: What technologies do you have access to and/or wish to use? What type of classroom do you have? Will tutors be present in class? Etc. 
3. Pedagogical design principles to implement: Will the activity include individual and/or team components? Will the activity extend to pre- and post-class? What knowledge and cognitive processes (Bloom's Taxonomy [20]) are students to obtain and achieve? Etc.

To highlight the process we will consider active learning pedagogies developed for a college classical mechanics course in a "versatile classroom."

In terms of discipline content, a reoccurring theme in classical mechanics is the analysis of forces. Whether the context is static equilibrium, translational and rotational dynamics, or conservation principles related to energy and momentum, students need to set up correct free body diagrams and to correctly analyze the forces acting on bodies. As a consequence, many of the activities that we have designed include a component where students must produce free body diagrams.

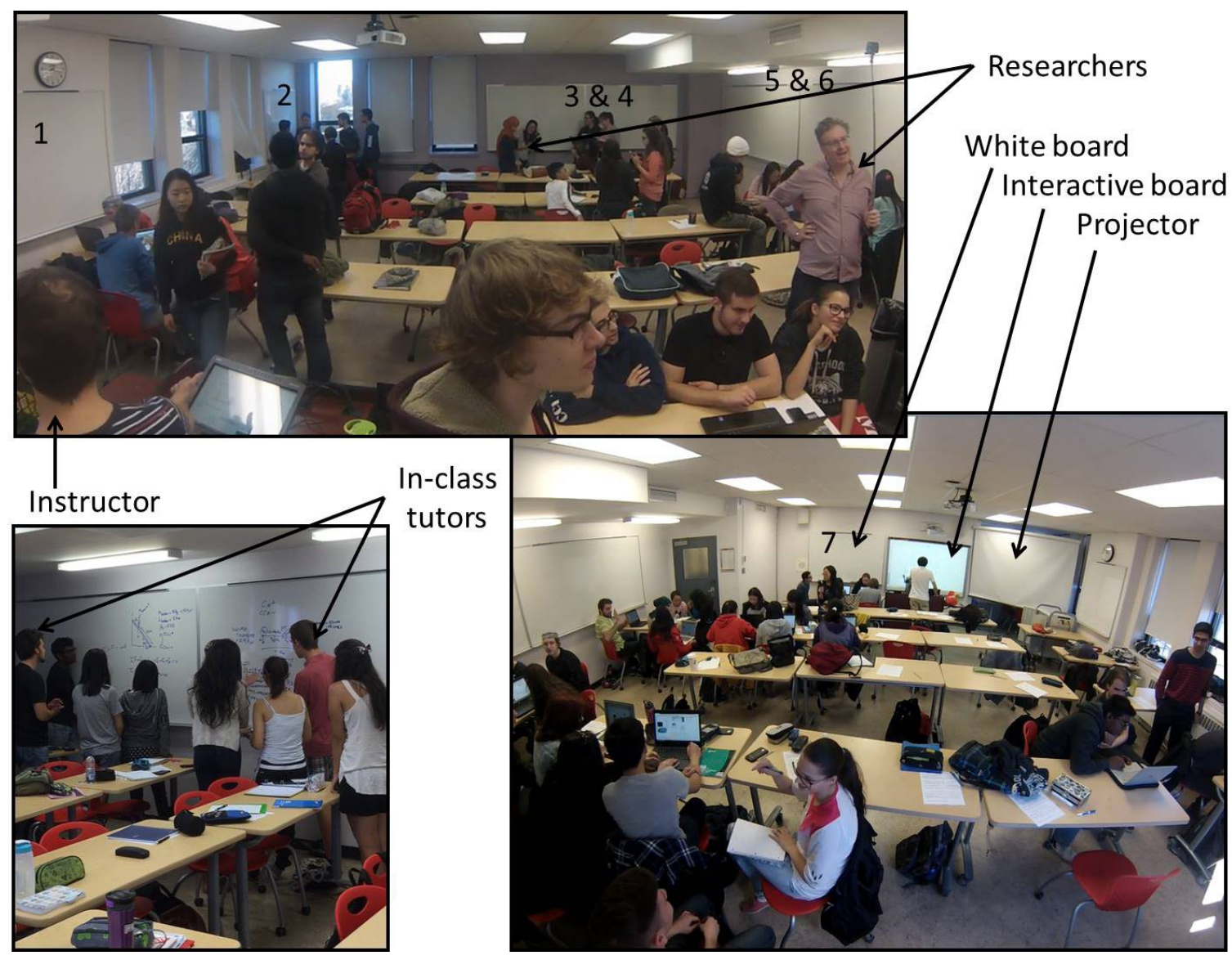

Figure 1: Versatile classroom with seven white boards along the perimeter of the room, an interactive board, a projector, and tables and chairs that can easily move. In addition to the instructor, researchers and in-class tutors are present.

Our versatile classrooms, presented in figure 1, are equipped with white boards along the perimeter of the room; one of these is in the front for instructor use and the rest are primarily for student use (e.g. to draw free body diagrams, brainstorming, problem solving, etc.). There is a projector and an interactive board (e.g. Smart board) for audiovisual display, annotation and saving, 15-20 laptops for student use, and tables and chairs that can easily move and be reconfigured for student groups. Digital platforms such as Smart Amp (smartamp.com), Visual Classrooms (visualclassrooms.com), and Phet simulations (phet.colorado.edu) are employed. The resources available to the instructor and the affordances of the room and technology allow activities to run outside the traditional spatial and temporal boundaries of a class; activities are designed to have pre-, in- and post-class components. Furthermore, it also allows each stage of the activity to have individual, group (or team) and class aspects. In addition, in-class tutors (second year students) are often available to assist the instructor in class, thus permitting flexibility with group size. 
A script, displayed in figure 2, has been developed to aid in the design of activities. Each step of the activity is defined by 1) when and where does the task take place; pre-, in- or post-class; in- or out-of-class? 2) Who performs the task(s); is it done individually, as a group, or as a class? 3) What type of tasks are involved; collection, collaboration, etc.? 4) What cognitive process is to be used, as defined by Bloom's taxonomy?

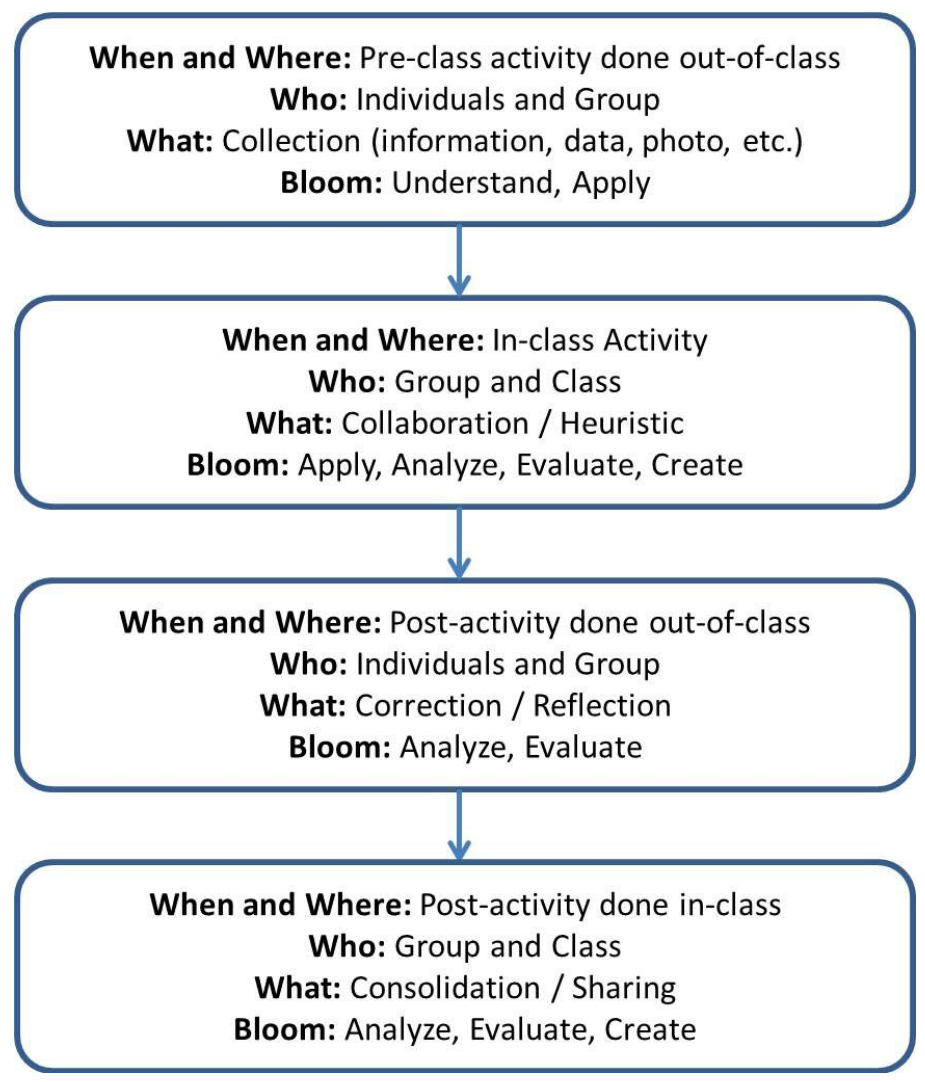

Figure 2: Script used to aid in the design of activities.

All of the designed activities involve students finding photos of an "everyday" event to be analyzed. The students are encouraged to take their own photos, be in the photo, or use a photo they find interesting from the internet. For example, in one such activity for conservation of linear momentum, students must find a sequence of photos of two interacting objects; before, during and after the interaction. Before coming to class, students need to upload their sequence of photos, prepare free body diagrams of the two interacting objects and provide a rationale. Each student is assigned to a group and each group has a digital group space (in Smart Amp or Visual Classrooms). The students can comment on each other's contribution prior to class. To help guide the students, the activity was constrained: in this case, each group had to showcase at least one example of each of the following features: 1) the mass of one of the objects is much greater than the other mass, 2) the change in total kinetic energy of the objects is small (approximating an elastic collision), 3) the change in total kinetic energy of the objects is large (approximating a totally inelastic collision), and 4) the initial velocity of both objects is zero. An example of a student entry is presented in figure 3 (a).

In-class, students work together in their groups in order to critique and correct their free body diagrams. The students are then to develop a heuristic for analyzing the free body diagrams of interacting objects (i.e. linking conservation of momentum of a system, impulse on an object, Newton's third law, etc.). They are then presented with a series of conceptual and quantitative questions to analyze and solve as a group using their heuristic. This activity lasts $1.5-2$ hours.

Post-class, the students upload their corrected free body diagrams, explain and reflect on what corrections were made, and finally, prepare a short question based on their photos. The students complete this in their assigned group space and 
comment on each other's final work until all students submit correct free body diagrams. The instructor has access to the group space; he/she can comment to a student or to the group and answer questions that students may still have. An example of a student final entry is provided in figure 3 (b).

Finally, there is a consolidation period in the following class where the instructor highlights the key learning objectives to the activity and shares the developed group heuristics.

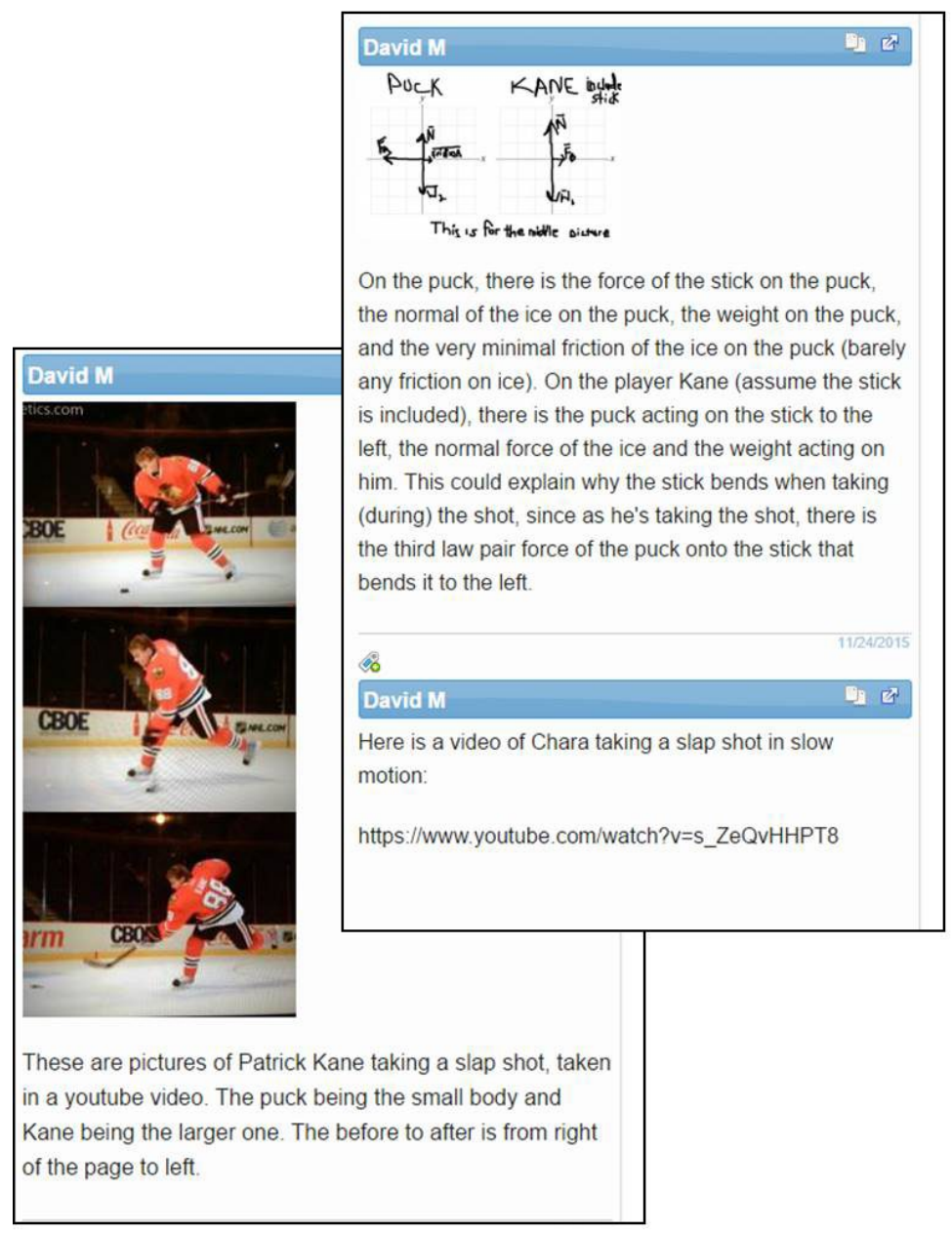

(a)

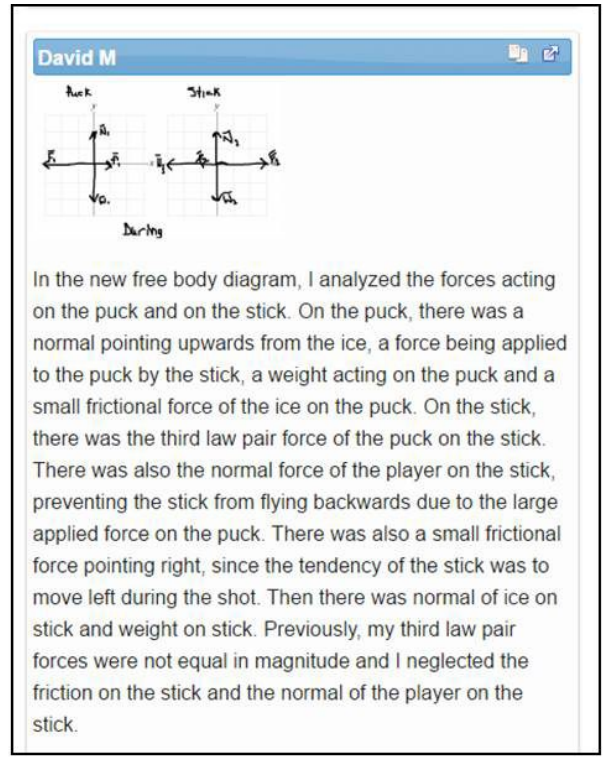

8

\section{David M Dis}

A puck is initially at rest on a frictionless ice surface. Patrick Kane is getting ready to take a slap shot. Before he take the slap shot, he winds up. As he is about to hit the puck, the direction of the velocity of the stick is 10 degrees below the horizontal from the wind up. The velocity in the $x$-direction is $15 \mathrm{~m} / \mathrm{s}$. He then hits the puck and it travels at 30 degrees above the horizontal to the ice and goes top corner. The mass of the stick is $5 \mathrm{~kg}$ and the mass of the puck is $0.050 \mathrm{~kg}$. After the shot, the stick lifts 5 degrees and moves to the right with a velocity of $10 \mathrm{~m} / \mathrm{s}$. What is the velocity of the puck when it hits the net?

(b)

Figure 3: Example of a student's contribution (a) pre-class and (b) post-class for conservation of linear momentum activity.

Several activities have been developed using the script. Variations of each activity have been adapted to the resources available; so that instructors teaching in different classrooms (in traditional rooms or in rooms with up to six interactive boards), or wish to use less digital technology can still accomplish the activity. In each case, how the activity is conducted and the level of student engagement can be compared.

These observations are part of a larger study conducted by the research team which is interested generally in orchestration. That is to say how activities are actually implemented in the classroom. For those classes that were documented, Go-Pro cameras were used to record video and audio (4 cameras total: 2 capturing the class as a whole and 2 capturing specific groups at work). These cameras have wide-angle lenses and are easy to attach around the classroom. Of particular interest is how instructors proceed through the activity script, and the interactions between the instructors and students, and between students themselves. Secondly, how student artifacts evolve over time (e.g. free body diagrams and heuristics), both at the individual and group levels, are examined. Finally, student answers and rationales to common 
test/exam questions among the instructors implementing the activities are also collected as the final arbiters of individual learning. These data answer questions like: did one class score higher for a question, did students use the heuristics developed in class, were there less errors about common misconceptions, etc.?

Not surprisingly, different instructors have different classroom implementations, and use the resources available differently, even though they collaborated on the design of the common activity. Most notable were the different times dedicated to the different parts of the activity. For one instructor, student discussion during the first part of the activity was short and less detailed. Rather, more time was spent consolidating the activity by focusing on the modeling segment. Another instructor shortened the first segment devoted to student discussions of their pre-class activity - i.e., the photos and free body diagrams. Instead, this instructor gave the students more time with the in-class problem solving. It should be noted, that students in all classes were engaged in meaningful discussions, which came out of the learning objectives of this activity.

Each instructor appeared to be implementing the activity based on several modifiers including personality, previous classroom experience, preferred teaching style, and confidence with technology and other available resources. Furthermore, students also react to the classroom resources and this also colors the instructor's interactions. The script design can either enhance or compete with these modifiers. One goal of co-design research is to bring enough flexibility to the discussion such that these modifiers can be identified and responded to in the activity design. This discussion requires a new vocabulary, a co-design language so-to-speak, which allows a fluid dynamic to exist between the researcher and the practitioner.

\section{MENTORING COLLEAGUES TO IMPLEMENT ACTIVE LEARNING PEDAGOGIES}

In 2016, the Faculty of Science at Vanier College implemented a mentoring initiative that allows instructors who wish to experiment with active learning pedagogies to get the necessary one-on-one support they need. Starting with the physics department, one author (RA) has taken on a mentoring role and is currently working with other instructors (mentees) to support them. Strategies include: one-on-one and group meetings to discuss active learning pedagogies, watching videos of unsuccessful and successful implementations of active learning pedagogies, visiting other instructors' classrooms (including the mentor's), having the mentor conduct or assist the mentee's activity (including team teaching), and having the mentor prepare all the on-line logistics when dealing with digital platforms. The goal is to ease colleagues into using active learning pedagogies, such that they are provided with a positive experience and then wish to continue using these pedagogies in the future.

Four colleagues with little experience with active learning pedagogies accepted to be mentored in the past academic year. There was an initial group meeting to share the activities that were already developed by the initial co-design process described previously. From that list of activities, each mentee then identified which ones they wanted to implement. Two one-on-one meetings occurred prior conducting an activity and one after. The first meeting was to discuss possible modifications to the activity in order to better suit the mentee's learning objectives and resources. Due to the mentees limited confidence with technology and/or the available resources in their classrooms, all mentees requested a version that was less dependent on digital platforms. The goal of the mentor was then to help each mentee modify their chosen activity accordingly; hence, a level of co-design between the mentor and mentee is established. The second meeting was to finalize the activity logistics. The post activity meeting was to discuss how it went and to brainstorm ideas for future improvements or modifications.

Most instructors were teaching in traditional classrooms. The pre-class component was designed using Microsoft products (Word and Power Point). Templates were developed such that students could individually prepare their pre-class work at home, print it, and bring to class. The only group component of the activity occurred in-class (students sitting in groups around a desk, all with their printed photos and free body diagrams). The post-class component was back to being purely individual; students had to correct their work and reflect at home before submitting a final product to the instructor.

Three of the four mentees chose to implement the in-class activity alone (i.e. without the presence of the mentor). The fourth mentee chose the team teaching approach. First, the mentor introduced the pre-class activity to the students a week 
beforehand. Then during the in-class activity, the mentor took a leading role while the mentee took on a supporting role in the implementation, yet both were equally involved when groups had questions.

Note that the implementation of each mentee's respective in-class activity was different to the mentor's implementation. Due to the absence of group work in the pre-class component, the mentees reported that they spent more time on providing instructions and setting up groups, and dedicated less time for group discussions than planned. This is an important factor to consider for future implementations. Yet, all mentees reported having a positive experience: the mentoring better prepared them in implementing and conducting the activity. They describe their students as being more engaged in class (i.e. students collaborated in their group work and stayed focus on the task at hand) compared to a regular lecture. Most importantly, they wish to redo the same activity for their next cohort, albeit in a more autonomous fashion, and wish to be mentored for a second activity. We wish to expand this initiative by 1) adding more mentees in the physics department and 2) collaborating with content experts in other departments to build active learning pedagogies and establishing mentorship programs for those departments too.

\section{COMMUNITY OF PRACTICE}

By engaging more instructors in active learning pedagogies, we have expanded our community of practice in the physics department and at the college. Informal meetings are regularly held where instructors are encouraged to share their experiences with active learning pedagogies; an exchange of ideas and expertise ensues. Workshops are also organized to allow instructors to experiment with digital technology and platforms.

Furthermore, collaborations between the science disciplines (physics, chemistry, biology and mathematics) have led to innovative approaches to teaching. The digital platforms allow for multiple instructors to access the same class or group space. This facilitates the implementation of multidisciplinary activities such as concept mapping and shared homework explicitly linking topics between disciplines, for example, kinematics and calculus.

\section{CONCLUSIONS}

We have presented how the Faculty of Science at Vanier College is getting more instructors to engage in active learning pedagogies by co-designing new active learning pedagogies with pedagogy researchers and through mentoring. The iterative co-designing process and its three aspects of activity design are illustrated. Active learning pedagogies developed for a college classical mechanics course taught in versatile classrooms have been highlighted: the activities are multi-stage (pre-, in- and post-class) and consists of both individual and group components. Researchers examine instructor orchestration styles, student artifacts and rationales to compare active learning pedagogies. Next, via mentoring, instructors are provided with support as they implement active learning pedagogies in their classrooms. Last, we have expanded our community of practice at the college via these initiatives. Our goal is to build on this experience, that is, co-design more active learning pedagogies for classical mechanics, and other physics and science courses, to support more mentees and to further expand our community of practice. Ultimately, by engaging more instructors in active learning pedagogies, more students will engage with class content, leading to a more positive experience for both instructors and students.

\section{ACKNOWLEDGMENTS}

The authors thank the members of SALTISE for their help and support, specifically Elizabeth Charles, Adamo Petosa, Chris Whittaker and Chao Zhang. The authors also thank their colleagues (mentees) for their participation.

\section{REFERENCES}

[1] Hake, R. R., "Interactive-engagement vs traditional methods: A six thousand-student survey of mechanics test data for introductory physics courses," American Journal of Physics, 66, 64-74 (1998). 
[2] Freeman, S., Eddy, S. L., McDonough, M., Smith, M. K., Okoroafor, N., Jordt, H., and Wenderoth, M. P., “Active learning increases student performance in science, engineering, and mathematics," Proc. Natl Acad Sci USA, 111 (23), 8410-8415 (2014).

[3] Weiman, C. E., "Large-scale comparison of science teaching methods sends clear message," Proc. Natl Acad Sci USA, 111 (23), 8319-8320 (2014).

[4] Watkins, J., and Mazur, E., "Retaining Students in Science, Technology, Engineering, and Mathematics (STEM) Majors," Journal of College Science Teaching, 42 (5), 36-41 (2013).

[5] Crouch, C. H., and Mazur, E., "Peer Instruction: Ten Years of Experience and Results," American Journal of Physics, 69, 970-977 (2001).

[6] Lasry, N., Mazur, E., and Watkins, J., "Peer instruction: From Harvard to the two-year college," American Journal of Physics, 76, 1066-1069 (2008).

[7] Zhang, P., Ding, L., and Mazur, E., "Peer Instruction in introductory physics: A method to bring about positive changes in students' attitudes and beliefs," Physical Review Physics Education Research, 13, 010104 (2017).

[8] Michael, J., "Faculty Perceptions about Barriers to Active Learning," College Teaching, 55, 42-47 (2007).

[9] Edwards, S., "Active learning in the middle grades classroom: Overcoming the barriers to implementation," Middle Grades Research Journal, 10 (2015).

[10] "Finding the Mass of a Car," Problem Based Learning for Mechanics, Video edited by Vanier College Television, Vanier College: http://vtv.vaniercollege.qc.ca/2014/12/science-car-mass-experiment/\#.VI4lUDHF-Cl (2014).

[11] Kalman, C. S., Aulls, M., Rohar, S., and Godley, J., "Students Perception of Reflective Writing as a Tool for Exploring an Introductory Textbook," Journal of College Science Teaching, 37, 74-81 (2008).

[12] Adams, R., Lenton, K., and Dedic, H., "ICT (\& TLC) improves student motivation in physics courses," Proc. Canadian Association of Physicists Annual Conference, poster 92 (2013).

[13] Lenton, K., and Adams, R., "Student-Generated Videos in the Physics Classroom," Canadian Association of Physicists - Physics in Canada Journal: Special Issue on Physics Education in Canada, 70 (2), 117-119 (2014).

[14] Miller, K., Zyto, S., Karger, D., Yoo, J., Mazur, E., “Analysis of student engagement in an online annotation system in the context of a flipped introductory physics class," Physical Review Physics Education Research, 12, 020143 (2016).

[15] Perkins, K., Adams, W., Dubson, M., Finkelstein, N. D., Reid, S., Wieman, K. and LeMaster, R., "PhET: Interactive Simulations for Teaching and Learning Physics," Physics Teacher, 44, 18-26 (2006).

[16] Petosa, A., Adams, R., Mulcair, G., Brotto, G. and Manley, L., "Leveraging Web-based Technologies to Enhance Collaborative Learning: SMART AMP," Workshop presented at Supporting Active Learning and Technological Innovation in Studies of Education (SALTISE) Annual Conference, Montréal, Québec (2016).

[17] Egan, K., Stout, M., and Takaya, K., [Teaching and Learning Outside the Box: Inspiring Imagination Across the Curriculum], Teachers College Press, New York (2007).

[18] Lima, J. and Adams, R., "Creativity in the Science Classes for Deeper Understanding," Proc. Colloque Annuel De L’Association Québecoise de Pédagogie Collégiale, paper 209 (2016).

[19] Bartley, J. E., Mayhew, L. M., and Finkelstein, N. D., "Promoting Children's Understanding And Interest In Science Through Informal Science Education," Proc. Physics Education Research Conference, AIP Press, 1179, 93-96 (2009).

[20] Heer, R., "Revised Bloom's Taxonomy," Iowa State University Center for Excellence in Learning and Teaching: http://www.celt.iastate.edu/teaching/effective-teaching-practices/revised-blooms-taxonomy (2012). 